Subscriber access provided by EDINBURGH UNIVERSITY LIBRARY | @ http://www.lib.ed.ac.uk

Letter

\title{
Molecular Docking Studies of Royleanone Diterpenoids from Plectranthus spp. as P-Glycoprotein Inhibitors
}

Vera M. S. Isca, Ricardo J Ferreira, Catarina Garcia, Carlos M. Monteiro, Jelena Dinic, Suvi holmstedt, Vania Andre, Milica Pesic, Daniel J. V. A. dos Santos, Nuno R. Candeias, Carlos A. M. Afonso, and Patrícia Rijo ACS Med. Chem. Lett., Just Accepted Manuscript • DOI: 10.1021/acsmedchemlett.9b00642 • Publication Date (Web): 12 Mar 2020

Downloaded from pubs.acs.org on March 12, 2020

\section{Just Accepted}

"Just Accepted" manuscripts have been peer-reviewed and accepted for publication. They are posted online prior to technical editing, formatting for publication and author proofing. The American Chemical Society provides "Just Accepted" as a service to the research community to expedite the dissemination of scientific material as soon as possible after acceptance. "Just Accepted" manuscripts appear in full in PDF format accompanied by an HTML abstract. "Just Accepted" manuscripts have been fully peer reviewed, but should not be considered the official version of record. They are citable by the Digital Object Identifier (DOI®). "Just Accepted" is an optional service offered to authors. Therefore, the "Just Accepted" Web site may not include all articles that will be published in the journal. After a manuscript is technically edited and formatted, it will be removed from the "Just Accepted" Web site and published as an ASAP article. Note that technical editing may introduce minor changes to the manuscript text and/or graphics which could affect content, and all legal disclaimers and ethical guidelines that apply to the journal pertain. ACS cannot be held responsible for errors or consequences arising from the use of information contained in these "Just Accepted" manuscripts. 


\title{
Molecular Docking Studies of Royleanone Diterpenoids from Plectranthus spp. as P-Glycoprotein Inhibitors
}

\author{
Vera M. S. Isca ${ }^{1,2}$, Ricardo J. Ferreira ${ }^{2,3^{*}}$, Catarina Garcia ${ }^{1,4}$, Carlos M. Monteiro ${ }^{2}$, Jelena Dinic ${ }^{5}$, Suvi Holmstedt ${ }^{6}$, Vânia
} André $^{7}$, Milica Pesic ${ }^{5}$, Daniel J. V. A. dos Santos ${ }^{2,8}$, Nuno R. Candeias ${ }^{6,9}$, Carlos A.M. Afonso ${ }^{2}$, Patrícia Rijo ${ }^{1,2 *}$

${ }^{1}$ Center for Research in Biosciences \& Health Technologies (CBIOS), Universidade Lusófona de Humanidades e Tecnologias, 1749-024 Lisboa, Portugal

${ }^{2}$ Instituto de Investigação do Medicamento (iMed.ULisboa), Faculdade de Farmácia, Universidade de Lisboa, 1649-003 Lisboa, Portugal

${ }^{3}$ Science for Life Laboratory, Department of Cell and Molecular Biology, Uppsala University, 75124 Uppsala, Sweden

${ }^{4}$ Department of Biomedical Sciences, Faculty of Pharmacy, University of Alcalá, Campus Universitario, 28871 Alcalá de Henares, Spain

${ }^{5}$ Institute for Biological Research "Siniša Stankovićc"- National Institute of Republic of Serbia University of Belgrade, Despota Stefana 142, 11060 Belgrade, Serbia

${ }^{6}$ Faculty of Engineering and Natural Sciences, Tampere University, Korkeakoulunkatu 8, 33101 Tampere, Finland

${ }^{7}$ Centro de Química Estrutural, Instituto Superior Técnico, Universidade de Lisboa, Av. Rovisco Pais 1, 1049-001 Lisboa, Portugal

${ }^{8}$ LAQV@REQUIMTE/Department of Chemistry and Biochemistry, Faculty of Sciences, University of Porto, Rua do Campo Alegre, 4169-007 Porto, Portugal

${ }^{9}$ LAQV-REQUIMTE, Department of Chemistry, University of Aveiro, 3810-193 Aveiro, Portugal

*shared senior authorship

KEYWORDS. Multidrug resistance, Plectranthus, royleanone derivatives, molecular docking, molecular dynamics, P-gp inhibition.

ABSTRACT: The development of multidrug resistance (MDR) is a major cause of failure in cancer chemotherapy. Several abietane diterpenes with antitumoral activities have been isolated from Plectranthus spp. such as 6,7-dehydroroyleanone (DHR, 1) and 7 $\alpha$ acetoxy-6 $\beta$-hydroxyroyleanone (AHR, 2). Several royleanone derivatives were prepared through hemi-synthesis from natural compounds 1 and 2, to achieve a small library of products with enhanced anti-P-glycoprotein activity. Nonetheless, some derivatives tend to be unstable. Therefore, in order to reasoning such lack of stability, the electron density based local reactivity descriptors condensed Fukui functions and dual descriptor were calculated for several derivatives of DHR. Additionally, molecular docking and molecular dynamics studies were performed on several other derivatives in order to clarify the molecular mechanisms by which they may exert their inhibitory effect in P-gp activity. The analysis on local reactivity descriptors was important to understand possible degradation pathways and to guide further synthetic approaches towards new royleanone derivatives. A molecular docking study suggested that the presence of aromatic moieties increases the binding affinity of royleanone derivatives towards P-gp. It further suggests that one royleanone benzoylated derivative may act as a non-competitive efflux modulator, when bound to the M-site. Future generation of novel royleanone derivatives will involve i) a selective modification of position $\mathrm{C}$ - 12 with chemical moieties smaller than unsubstituted benzoyl rings and ii) the modification of the substitution pattern of the benzoyloxy moiety at position C-6.

While cancer is one of the leading causes of death worldwide, ${ }^{1}$ the development of multidrug resistance (MDR) is a major cause of failure in traditional cancer chemotherapy. ${ }^{2}$
Development of MDR is often associated with mutations and/or overexpression of ABC (ATP-binding cassette) family of membrane transport proteins such as $\mathrm{ABCB} 1$, also known as 
MDR1 or P-glycoprotein (P-gp). P-gp is a key player in the MDR by mediating ATP-dependent efflux of many anticancer drugs, decreasing their intracellular concentration and thus conferring resistance to these agents. ${ }^{3,4}$ Nevertheless, other events, such as deregulation in the apoptosis signaling, are also accountable for the phenomenon of MDR. ${ }^{5}$

The isolation of new natural products provides novel scaffolds with potential biological activities for cancer therapy. Several Plectranthus species (Lamiaceae) have been used in traditional medicine. ${ }^{6}$ The most commonly reported secondary metabolites in this genus are diterpenoids, mainly abietane quinones. Several abietane diterpenes isolated from Plectranthus spp. have been described as antimicrobial, antifungal, and cytotoxic. $^{7-10}$ Compound 6,7dehydroroyleanone (DHR, 1, Figure 1) is the main component of $P$. madagascariensis (Pers.) Benth essential oil, and exhibits several interesting bioactivities. ${ }^{11}$ The cytotoxic diterpene $7 \alpha$ -

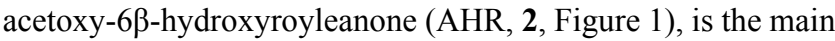
metabolite of $P$. grandidentatus extracts. ${ }^{8}$ The reported bioactivities and molecular structures suitable for derivatization make DHR and AHR attractive leads to the drug discovery process.

In previous works, ${ }^{12-15}$ more than twenty royleanone derivatives were prepared through hemi-synthesis from lead molecules $\mathbf{1}$ and $\mathbf{2}$. The hemi-synthetic derivatives were prepared aiming at building a library of compounds with enhanced cytotoxic potential regarding P-gp inhibition. In the present work, we report our studies on the most promising synthesized derivatives regarding stability and overall reaction yield. The compound 6,7-dihydroroyleanone (3, Figure 1) was obtained by basic hydrolysis of compound 2. Additionally, compounds $\quad 7 \alpha$-acetoxy- $6 \beta$-(4-chloro)benzoyloxy-12-O-(4chloro)benzylroyleanone (4, Figure 1) and $7 \alpha$-acetoxy- $6 \beta$ benzoylroyleanone $(\mathbf{5}$, Figure 1$)$ were obtained from benzoylation of the same starting material. The cytotoxic activity of compounds $\mathbf{1}, \mathbf{2}$ and $\mathbf{3}$ was assayed in non-small cell lung cancer (NCI-H460) and its MDR variant (NCI-H460/R), which overexpress the P-pg. Royleanones 1, 2 and $\mathbf{3}$ displayed ability to inhibit both cancer cell lines (NCI-H460 and NCIH460/R). ${ }^{8,16}$ Additionally, in a recent study, the diterpene 4 exhibited promising P-gp inhibition, with highest toxicity in NCI-H460 and NCI-H460/R lines, when compared to the compounds $\mathbf{1}, \mathbf{2}$ and $3 .{ }^{15}$ The anti-Pgp activity was never assess for royleanone $\mathbf{5}$.
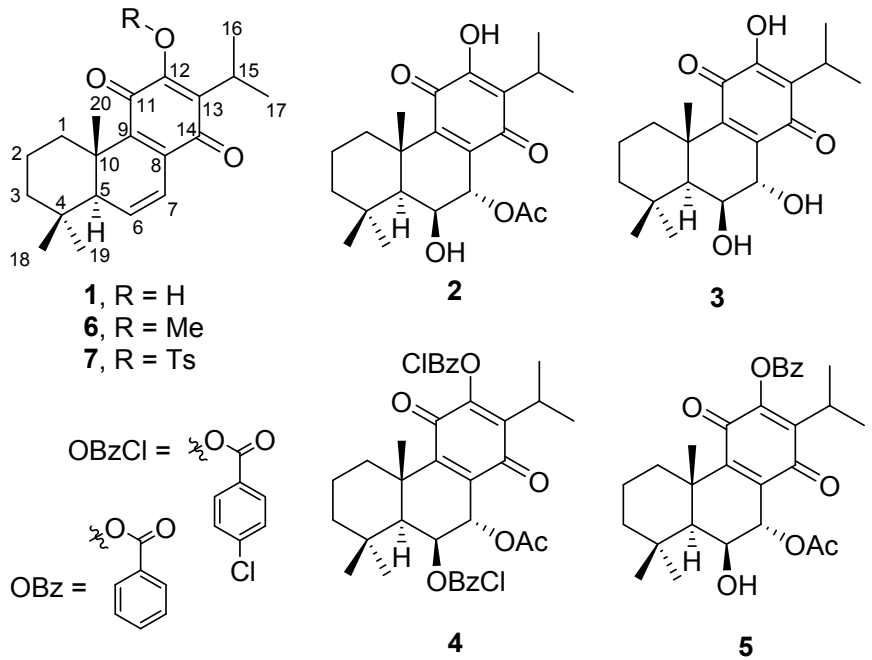

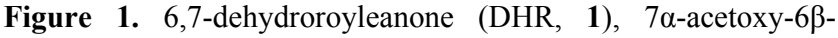

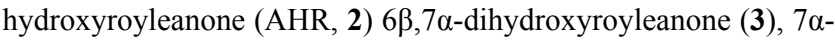
acetoxy-6 $\beta$-(4-chloro)benzoyloxy-12-O-(4chloro)benzoylroyleanone (4) and $7 \alpha$-acetoxy-6 $\beta$-hydroxy-12-Obenzoylroyleanone (5).

Several reactions were performed in the natural compounds 1 and $\mathbf{2}$ and some substrate diversity was tested with the intention of achieving compounds with enhanced cytotoxic potential. Nonetheless the broad diversity tested, several derivatives presented stability issues in the isolation process. For instance, all derivatives obtained by microwave-assisted Mitsunobu reaction of $\mathbf{1}$ and $\mathbf{2}$ were found to be unstable and, thus, unable to be isolated and/or further characterized. On the other hand, the hydrogenation, methylation or benzoylation reactions of 1 or 2 resulted in stable products. Several attempts to tosylate compound 1 led to formation of a single product as judged by TLC and the presence of 7 was identified by ${ }^{1} \mathrm{H}-\mathrm{NMR}$ of crude mixture. However, attempts for its isolation were unsuccessful due to decomposition, although the presence of the desired compound could be confirmed by HRMS.

Therefore, in order to get insight on the causes of such lack of stability, the electron density based local reactivity descriptors condensed Fukui functions ${ }^{17,18}$ and dual descriptor were calculated for the DHR (1), methylated (6) and tosylated (7) derivatives. Herein, Fukui functions have the capability of revealing the presence of nucleophilic and electrophilic regions within a molecule or a given scaffold, thus providing clues on the decomposition pathways that may have been followed by royleanone derivatives. Starting with neutral species, their geometry was firstly optimized at PBE1PBE/6-31G(d,p) level of theory. The natural bond orbitals of the neutral, cation and anion species were used for determination of the electrophilic $\left(f_{k}^{-}\right)$, nucleophilic $\left(f_{k}^{+}\right)$and radical attacks $\left(f_{k}^{0}\right)$ functions and their condensed versions for carbon and oxygen atoms are presented in Table 1. The condensed Fukui functions are calculated according to the following equations:

$$
\begin{aligned}
& f_{k}^{+}=\left[q_{k}(N+1)-q_{k}(N)\right], \text { for nucleophilic attack (1) } \\
& f_{k}^{-}=\left[q_{k}(N)-q_{k}(N-1)\right], \text { for electrophilic attack (2) } \\
& f_{k}^{0}=\left[\frac{q_{k}(N+1)-q_{k}(N-1)}{2}\right], \text { for radical attack (3) }
\end{aligned}
$$


where $k$ is the numbering of the atomic site and $q_{K}$ stands for the total natural population in the neutral $(\mathrm{N})$, anionic $(\mathrm{N}+1)$ and cationic (N-1) species. The dual descriptor $\left(\Delta f_{k}\right)$, a more accurate local reactivity descriptor ${ }^{19-21}$, was obtained in its condensed form according to the following equation,

$$
\Delta f_{k}=f_{k}^{+}-f_{k}^{-} \text {(4). }
$$

The $O$-substitution of the hydroxyl at position 12 has a noticeable impact on the Fukui functions $f_{k^{-}}$values for electrophilic attack at C-6, C-9 and C-13. While higher propensity for an electrophilic addition in $\mathbf{1}$ is observed at $\mathrm{C}-13$ (with comparable descriptor at C-6 and C-9), subtle changes are observed in $\mathbf{6}$, and higher reactivity should be expected at C-6 for 7 while position $\mathrm{C}-13$ is less prone for such reaction. Although tosylation of $\mathrm{O}-12$ ' has a significant impact on $f_{k}$ when compared with 1 (probably due to its electronwithdrawing nature), $O$-methylation (electron-donating group) in $\mathbf{6}$ does not change the value significantly.

Examination of the Fukui functions $f_{k}^{+}$suggest that the oxygen atoms of the quinone system are likely to have the highest propensity towards a nucleophilic attack, regardless the $O$-substitution which is in line with its propensity for reduction. A noticeable decrease of this index was determined for C- 6 and
C-11 upon tosylation in 7, while only subtle differences for such positions were visible when comparing $\mathbf{1}$ and $\mathbf{6}$. Indeed, the propensity for a nucleophilic attack in 7 at $\mathrm{C}-11$ and $\mathrm{C}-14$ is similar, contrasting with the higher electrophilic character of C11 compared with $\mathrm{C}-14$ in $\mathbf{1}$ and 6. Considering the susceptibility for reacting with a radical, while $O$-methylation seems to have little effect on radical susceptibility of C-9, $O$ tosylation in 7 increases considerably the reactivity at such position. This is also enforced by the electron's withdrawal of tosyl group and the donation of electrons by the methyl group.

Further information can be obtained from the analysis of the dual descriptor. $\mathbf{1}$ and $\mathbf{6}$ are more likely to react as electrophiles upon reaction at $\mathrm{C}-11$ with a nucleophile, while $\mathrm{C}-7$ will be the preferred site for electrophilic reaction. Although a similar trend is visible for 7 , the value of the dual descriptors is significantly altered in comparison with $\mathbf{1}$ and $\mathbf{6}$. From Table 1 is visible that C-7 is more likely to react with electrophiles in 7 than in $\mathbf{1}$ and $\mathbf{6}$, whilst an opposing tendency is observed for C11 , i.e. this carbon is less likely to react with nucleophiles in 7 when compared with $\mathbf{1}$ and $\mathbf{6}$. Relevantly, introduction of $O$ tosylate changes the electronic nature at $\mathrm{C}-12$, with this position being somewhat more likely to undergo nucleophilic attack in 7, rather than electrophilic reaction as expected for $\mathbf{1}$ and $\mathbf{6}$.

Table 1. Values of the condensed Fukui functions in DHR (1), methylated (6) and tosylated (7) derivatives computed from natural population analysis in gas phase.

\begin{tabular}{|c|c|c|c|c|c|c|c|c|c|c|c|c|}
\hline Atom & \multicolumn{3}{|c|}{$f_{\mathrm{k}}^{-}$} & \multicolumn{3}{|c|}{$f_{\mathrm{k}}^{+}$} & \multicolumn{3}{|c|}{$f_{\mathrm{k}}^{0}$} & \multicolumn{3}{|c|}{$\Delta f_{\mathrm{k}}$} \\
\hline & 1 & 6 & 7 & 1 & 6 & 7 & 1 & 6 & 7 & 1 & 6 & 7 \\
\hline C1 & $\begin{array}{l}-0.004 \\
\end{array}$ & -0.004 & -0.004 & -0.003 & -0.003 & -0.003 & -0.004 & -0.003 & -0.003 & 0.000 & 0.001 & 0.001 \\
\hline $\mathrm{C2}$ & -0.005 & -0.005 & -0.005 & -0.005 & -0.005 & -0.004 & -0.005 & -0.005 & -0.005 & 0.000 & 0.000 & 0.001 \\
\hline $\mathrm{C3}$ & -0.006 & -0.006 & -0.006 & -0.005 & -0.005 & -0.005 & -0.006 & -0.006 & -0.005 & 0.000 & 0.000 & 0.001 \\
\hline C4 & -0.004 & -0.004 & $\begin{array}{l}-0.004 \\
\end{array}$ & $\begin{array}{l}-0.004 \\
\end{array}$ & -0.004 & -0.003 & -0.004 & -0.004 & -0.004 & 0.000 & 0.001 & 0.001 \\
\hline C5 & -0.018 & -0.018 & -0.019 & -0.014 & -0.013 & -0.011 & -0.016 & -0.015 & -0.015 & 0.004 & 0.005 & 0.008 \\
\hline C6 & 0.140 & 0.140 & 0.153 & 0.124 & 0.112 & 0.097 & 0.132 & 0.126 & 0.125 & -0.016 & -0.028 & -0.056 \\
\hline C7 & 0.061 & 0.059 & 0.089 & -0.040 & -0.039 & -0.038 & 0.011 & 0.010 & 0.025 & -0.101 & $\begin{array}{l}-0.098 \\
\end{array}$ & -0.127 \\
\hline C8 & 0.018 & 0.026 & 0.029 & 0.098 & 0.082 & 0.061 & 0.058 & 0.054 & 0.045 & 0.080 & 0.057 & 0.031 \\
\hline C9 & 0.134 & 0.126 & 0.144 & 0.041 & 0.046 & 0.051 & 0.087 & 0.086 & 0.097 & $\begin{array}{c}-0.093 \\
\end{array}$ & -0.080 & -0.093 \\
\hline C10 & -0.010 & -0.009 & -0.011 & -0.005 & -0.005 & -0.005 & -0.008 & -0.007 & -0.008 & 0.005 & 0.004 & 0.005 \\
\hline C11 & -0.031 & -0.029 & -0.026 & 0.116 & 0.107 & 0.086 & 0.043 & 0.039 & 0.030 & 0.147 & 0.137 & 0.112 \\
\hline O11' & 0.055 & 0.056 & 0.057 & 0.133 & 0.138 & 0.133 & 0.094 & 0.097 & 0.095 & 0.078 & 0.082 & 0.076 \\
\hline C12 & 0.041 & 0.041 & 0.032 & 0.015 & 0.031 & 0.050 & 0.028 & 0.036 & 0.041 & -0.026 & -0.010 & 0.017 \\
\hline O12' & 0.077 & 0.073 & 0.027 & 0.046 & 0.030 & 0.010 & 0.061 & 0.052 & 0.019 & -0.031 & -0.043 & -0.018 \\
\hline $\mathrm{C13}$ & 0.144 & 0.131 & 0.069 & 0.049 & 0.048 & 0.050 & 0.097 & 0.090 & 0.060 & -0.095 & -0.083 & -0.019 \\
\hline C14 & $\begin{array}{l}-0.027 \\
\end{array}$ & -0.028 & -0.025 & 0.058 & 0.068 & 0.084 & 0.016 & 0.020 & 0.029 & 0.086 & 0.097 & 0.109 \\
\hline O14' & 0.063 & 0.058 & 0.044 & 0.127 & 0.129 & 0.129 & 0.095 & 0.093 & 0.086 & 0.064 & 0.071 & 0.085 \\
\hline C15 & -0.018 & -0.017 & -0.009 & -0.011 & -0.010 & -0.010 & -0.014 & -0.014 & -0.010 & 0.007 & 0.006 & -0.001 \\
\hline C16 & -0.003 & -0.002 & -0.003 & -0.006 & -0.006 & $\begin{array}{l}-0.006 \\
\end{array}$ & -0.005 & -0.004 & -0.004 & -0.003 & -0.004 & -0.003 \\
\hline C17 & -0.002 & -0.002 & -0.003 & -0.006 & -0.006 & -0.006 & -0.004 & -0.004 & -0.004 & -0.004 & -0.004 & -0.003 \\
\hline C18 & $\begin{array}{l}-0.006 \\
\end{array}$ & -0.006 & -0.006 & $\begin{array}{l}-0.006 \\
\end{array}$ & -0.006 & $\begin{array}{l}-0.005 \\
\end{array}$ & -0.006 & -0.006 & -0.006 & 0.000 & 0.000 & 0.001 \\
\hline C19 & -0.007 & -0.007 & -0.007 & -0.007 & -0.007 & -0.006 & -0.007 & -0.007 & -0.007 & 0.000 & 0.001 & 0.001 \\
\hline
\end{tabular}




\begin{tabular}{|c|c|c|c|c|c|c|c|c|c|c|c|c|}
\hline $\mathrm{C20}$ & 0.006 & 0.007 & 0.009 & -0.006 & -0.005 & -0.005 & 0.000 & 0.001 & 0.002 & -0.012 & -0.012 & -0.014 \\
\hline $\mathbf{R}$ & 0.019 & -0.013 & 0.053 & 0.014 & -0.012 & 0.039 & 0.017 & -0.013 & 0.046 & -0.005 & 0.002 & -0.014 \\
\hline
\end{tabular}

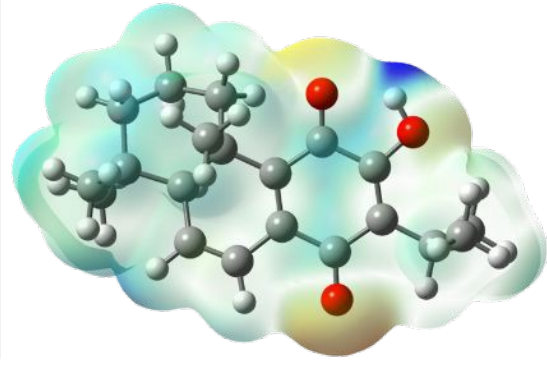

1

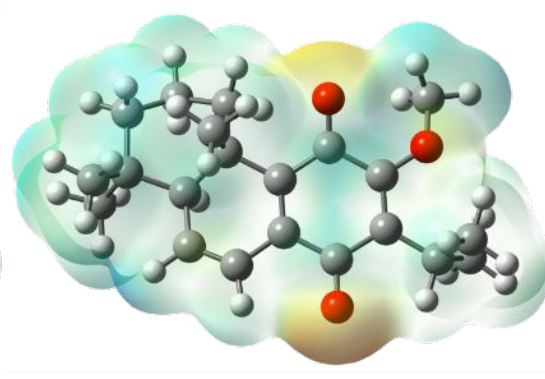

6

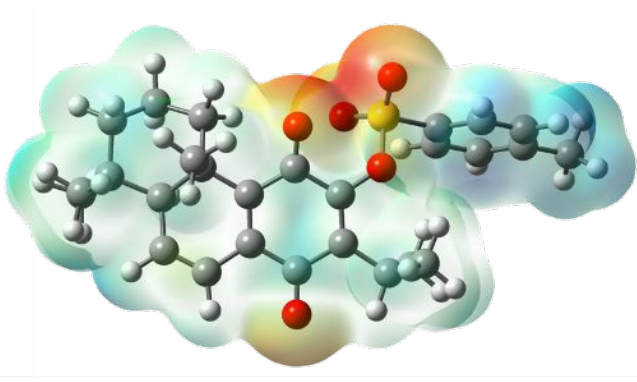

7

Figure 2. The total electron density mapped with the molecular electrostatic potential surfaces of 1, 6 and 7 .

The electron density analysis of electrostatic potential surfaces of the three compounds (Figure 2) shows a localized electron density around the tosyl group in 7 , while a deficit of density is observed in the same region in $\mathbf{1}$ due to the acidity of the enol. Overall, this analysis might suggest that the higher decomposition of the tosylated derivative $\mathbf{7}$ compared to $\mathbf{1}$ and 6 can come from two main factors: the increased reactivity towards radicals at position $\mathrm{C}-9$ and increased reactivity of C7 towards electrophiles.

The above analysis on local reactivity descriptors was important not only to understand possible degradation pathways but also to guide further synthetic approaches towards new royleanone derivatives. To that matter, studying the compounds that were successfully synthesized and that efficiently inhibited P-gp (4-5) is also of the utmost importance. Herein, both molecular docking (for compounds 1-5) and molecular dynamics studies (4 and 5) were performed in order to clarify the molecular mechanisms by which they exert their inhibitory effect. Additionally, three other theoretical derivatives, $7 \alpha$-acetoxy-6 $\beta$-(4chloro)benzoyloxyroyleanone (4a), $\quad 7 \alpha$-acetoxy-12-O-(4chloro)benzoylroyleanone (4b) and $7 \alpha$-acetoxy-6 $\beta$ benzoyloxyroyleanone (5a) were studied to evaluate the importance of the substituents and its substitution pattern in each position suitable for derivatization. In both studies a refined murine P-gp structure ${ }^{22}$ and the location of drugbinding sites (M- R- and H-sites) were retrieved from a previous publication (additional data on the drug-binding sites available at the Supporting Information). ${ }^{23}$

The herein results (Table 2) clearly show that the presence of additional aromatic moieties increases compound $\mathbf{4}$ binding affinity towards P-gp, decreasing its $\Delta G_{\text {bind }}$ by 2.8 - 3.1 kcal.mol ${ }^{-1}$ and 0.9 - $1.8 \mathrm{kcal}^{\mathrm{mol}}{ }^{-1}$ (for $\mathrm{R}$ and $\mathrm{M}$ sites, respectively). Interestingly, the presence of additional binding poses at the substrate-binding $\mathrm{H}$ site $\left(-10.5 \mathrm{kcal}^{\mathrm{mol}}{ }^{-1}\right)$ suggests an additional competitive mechanism, occurring at both the substrate-binding $\mathrm{R}$ - and $\mathrm{H}$-sites, as one of the principal modes of action for royleanone derivative 4 . As similar results were obtained for compound $\mathbf{5}$ and $\mathbf{5 a}$ (Table 2 ), the docking results seem to suggest that moieties at position C-6 may render more potent inhibitors due to the additional interactions with the Hoescht-33342 binding H-site (additional information on the P-gp drug-binding sites provided in the Supporting Information).

Table 2. Docking results, cross-interaction capability (CIc) and protein-ligand contacts for the tested compounds obtained by LigPlot.

\begin{tabular}{|c|c|c|c|c|c|c|c|}
\hline & \multicolumn{3}{|c|}{$\begin{array}{c}\text { Top-ranked affinity } \\
\text { kcal.mol-1 (nr. of poses) }^{-1}\end{array}$} & \multirow[t]{2}{*}{ CIc } & \multicolumn{3}{|c|}{$\begin{array}{c}\text { Residues } \\
\text { (no. interactions) }\end{array}$} \\
\hline & H-site & R-site & M-site & & Aro & Hyd & Pol \\
\hline 1 & -- & $-8.8(4)$ & $-8.6(5)$ & $\mathrm{M}$ & $5(23)$ & $2(2)$ & $4(8)$ \\
\hline 2 & -- & $-8.7(4)$ & $-9.2(5)$ & $\mathrm{W}$ & $4(10)$ & $5(9)$ & $4(3)^{*}$ \\
\hline 3 & -- & $-8.5(4)$ & $-9.5(5)$ & $\mathrm{W}$ & $6(24)$ & $2(4)$ & $5(10)$ \\
\hline 4 & $-10.5(2)$ & $-11.6(3)$ & $-10.4(4)$ & $\mathrm{S}$ & $5(13)$ & $5(13)$ & $3(4)^{*}$ \\
\hline $4 a$ & $-9.2(1)$ & $-10.2(4)$ & $-10.3(4)$ & $\mathrm{S}$ & $5(14)$ & $4(9)$ & $2(8) * *$ \\
\hline $4 b$ & -- & $-9.3(3)$ & $-9.2(6)$ & $\mathrm{M}$ & $5(11)$ & $4(5)$ & $4(11)^{* *}$ \\
\hline 5 & -- & $-9.3(4)$ & $-9.9(5)$ & $\mathrm{S}$ & $5(17)$ & $4(9)$ & $5(13)^{+}$ \\
\hline $5 a$ & $-9.2(1)$ & $-10.4(2)$ & $-10.7(6)$ & $\mathrm{S}$ & $5(15)$ & $5(7)$ & $3(3)^{*}$ \\
\hline
\end{tabular}

The binding energies refer to the top-ranked pose at each of the considered drug-binding sites. Hydrogen bonds with Ser697 and Ser943 $\left(^{*}\right)$, with Ser693 $\left(^{* *}\right)$ or Thr297 $\left(^{+}\right)$were observed. From a previous study, ${ }^{23}$ docking binding energies for Rhodamine-123 were -9.2 kcal.mol ${ }^{-1}$ at both $\mathrm{M}$ - and R-sites. Regarding CIc: W, weak; M, moderate; $\mathrm{S}$, strong (more information on CIc at the Supporting Information).

Nonetheless, low binding energies together with a strong cross-interaction capability $(\mathrm{CIc})^{23}$ when at the M-site also allow us to infer that $\mathbf{4}$ and $\mathbf{5}$ may also act as a non-competitive efflux inhibitors at the M-site. From the additional scaffolds (compound 4a, 4b and 5a) only the substituent at position C6 seems particularly relevant for improving the biological activity, encompassing good binding affinities at both $\mathrm{M}$ - and R-sites, strong CIc's at the M-site and additional interactions with the $\mathrm{H}$-site. Interestingly, when at the position $\mathrm{C}-12$, the presence of the additional chlorine at the para position of the substituent i) seem to have a detrimental effect on the CIc (from strong to moderate) but without significantly changing the binding energies and ii) is enough to shift the top-ranked binding pose of compound $\mathbf{4}$ from the M- to the substratebinding R-site. 
Docking results also confirm that, for compound 4 (Figure S1B), while the 4-chlorobenzoyl substituent at position C-6 is deeply buried at the top of the M-site, in close vicinity to Phe71, Thr75 and Leu971, the substituent at position C-12 is oriented towards the water-filled cavity and not participating in significant interactions with the protein. Similarly, in all monosubstituted compounds the substituent is also found to be buried and close to the apex of the M-site. Therefore, the initial data obtained from molecular docking studies uphold the importance of the benzoyloxy substituent for the inhibitory activity displayed by the royleanone derivatives, while suggesting that in other position this moiety can be replaced by other moieties either more prone to establish additional interactions with P-gp's or to fine-tune the physicochemical properties of the derivatives.

From the top-ranked poses obtained from the docking studies, a molecular dynamics (MD) study followed. Herein and as only $\mathbf{4}^{15}$ and $\mathbf{5}$ revealed to be stronger P-gp inhibitors, as assessed by a Rhodamine-123 accumulation assay, the MD approached focused on unveiling the molecular mechanism by which these compounds are able to inhibit efflux. To assess the importance of C-6/C-12 substituents in conferring stability to the derivatives under study, the relative importance of the substituents at both positions were additionally evaluated by studying the theoretical derivatives $4 \mathbf{a}, \mathbf{4 b}$ and 5a. 40-ns MD simulations were performed. Herein, and due to the high flexibility of the transporter, longer MD simulations are expected to mask any effects that the ligand may have in the transporter and vice-versa. Thus, only the last 20-ns of the MD run were considered production and analyzed.

Firstly, the relative free-energy of binding was estimated through a MM/PBSA approach, corrected to encompass the presence of a lipid bilayer through an implicit membrane approach (Table 3). ${ }^{24}$ From the data obtained, it is possible to infer that i) the presence of a second benzoyloxy moiety does not significantly contribute to the binding affinity towards Pgp and that ii) the presence of a para substitution decreases the calculated $\Delta G_{\text {bind }}$ by $\sim 10 \mathrm{kcal} . \mathrm{mol}^{-1}$. These results agree with the docking predictions in which only one benzoyloxy moiety is needed to promote stronger interactions with P-gp, but nonetheless they allow us to infer additional insights about the role that aromatic substitution may have on the interaction with the transporter. For comparison purposes, the relative free energy of binding of compound $\mathbf{4}$ at the substrate-binding R-site was calculated to be $-71.0 \pm 5.4 \mathrm{kcal}^{\mathrm{mol}}{ }^{-1}$.

The analysis of the protein-ligand hydrogen-bond network revealed that the existing HB network is reinforced through a decrease in $\mathrm{HB}$ formation energy while increasing the HB lifetime increases (Table 3), due to interactions with Tyr303/Tyr949 (4a) and Gln191/Tyr949 (4b). For compounds 5 and $\mathbf{5 a}, \mathrm{HBs}$ with Gln721 are the most predominant ones. Significant differences were also registered in ligand efficiency (LE), herein calculated as the ratio between the number of protein-ligand contacts with frequencies greater than 0.50 and the total number of registered protein-ligand contacts (for additional information see Methods section in Supporting Information file). Despite the HB reinforcement, compound $\mathbf{4 b}$ registered a dramatic decrease in its ligand efficiency $(\mathrm{LE}=0.08)$ when compared with both compounds $4, \mathbf{4 a}, \mathbf{5}$ and $\mathbf{5 a}(\mathrm{LE}=0.29 \pm 0.01)$. Herein, a closer inspection revealed that during the MD production run $\mathbf{4 b}$ shifted to a lower position inside the pocket (Figure S2), most probably due to the presence of the para substituent. This was corroborated when evaluating CIc during the MD simulations. For compound $\mathbf{4}$ was calculated to be CIc $=0.71$, slightly decreasing in $4 \mathbf{a}(\mathrm{CIc}=0.66)$ and having an even greater decrease in $4 \mathbf{b}(\mathrm{CIc}=0.55)$. Oppositely, both compounds $\mathbf{5}$ and $\mathbf{5 a}$ registered a substantial increase (CIc $=0.95$ and 0.92 , respectively). Therefore, it is clear that the presence of an aromatic para-substitution reduces the ability of the compounds in establishing sufficient cross-interactions to impair the conformational changes that are thought to mediate efflux, especially when the substituent is located at position C-12.

Table 3. Data from MD simulations for compounds 4, 4a, $4 b, 5$ and $5 a$.

\begin{tabular}{|c|c|c|c|c|c|}
\hline & 4 & $4 a$ & $4 \mathbf{b}$ & 5 & $5 \mathbf{a}$ \\
\hline \multicolumn{6}{|c|}{ Molecular Mechanics/Poisson-Boltzmann Surface Area } \\
\hline $\begin{array}{l}\Delta G_{\text {bind }} \\
\mathrm{kcal} \mathrm{mol}^{-1}( \pm \mathrm{SD})\end{array}$ & \begin{tabular}{|l|}
-78.5 \\
$( \pm 4.4)$
\end{tabular} & \begin{tabular}{|c|}
-72.4 \\
$( \pm 4.4)$
\end{tabular} & $\begin{array}{l}-70.0 \\
( \pm 4.0)\end{array}$ & $\begin{array}{c}-87.7 \\
( \pm 5.0)\end{array}$ & $\begin{array}{c}-84.2 \\
( \pm 4.6)\end{array}$ \\
\hline \multicolumn{6}{|c|}{ Hydrogen Bonding } \\
\hline$\left\langle N_{H B}\right\rangle$ & 1.806 & 1.861 & 1.413 & 1.731 & 0.861 \\
\hline$\Delta G_{H B}\left(\mathrm{~kJ} . \mathrm{mol}^{-1}\right)$ & -20.8 & -24.8 & -25.1 & -21.7 & -20.1 \\
\hline$\tau(\mathrm{ps})$ & 490 & 2363 & 2613 & 700 & 377 \\
\hline \multicolumn{6}{|c|}{ Protein-Ligand interactions } \\
\hline ligand efficiency & $\begin{array}{c}0.29 \\
(7 / 23)\end{array}$ & $\begin{array}{c}0.30 \\
(6 / 20)\end{array}$ & $\begin{array}{c}0.08 \\
(2 / 23)\end{array}$ & $\begin{array}{c}0.27 \\
(6 / 22)\end{array}$ & $\begin{array}{c}0.29 \\
(5 / 17)\end{array}$ \\
\hline $\mathrm{CIc}$ & 0.71 & 0.66 & 0.55 & 0.95 & 0.92 \\
\hline \multicolumn{6}{|c|}{ Oil-water partition coefficient } \\
\hline $\begin{array}{l}\text { molinspiration } \\
\log P\end{array}$ & 8.91 & 6.72 & 6.38 & 5.45 & 5.79 \\
\hline
\end{tabular}

In addition to the results obtained from both molecular docking and molecular dynamics studies, the physicochemical properties of the compounds $\mathbf{4 a}, \mathbf{4 b}, \mathbf{5}$ and $\mathbf{5 a}$, namely its octanol-water partition coefficient $(\log P),{ }^{25}$ become important because an effective P-gp inhibitor must be able to diffuse into and build up inside the lipid bilayer from the extracellular compartment. ${ }^{26}$ Herein, the calculated $\log P$ for all monosubstituted derivatives is within the optimal range calculated for other diterpenic compounds, oppositely to that calculated for compound $\mathbf{4}$ (Table 3).

Experimental validation. We have additionally confirmed our in silico findings by analyzing Rhodamine 123 accumulation in MDR cancer cells (Table 4). By means of compound $\mathbf{5}$ (the only one synthesized so far, having only one benzoyloxy substituent at position $\mathrm{C}-12$, as confirmed by the 
crystal structure determined from single crystal X-ray diffraction data - see details in Supporting Information), the observed MDR-reversal activity is similar to than in compound $\mathbf{4}$ and comparable to the control (Dex-VER), thus corroborating the importance of an unsubstituted aromatic substituent for the MDR reversal activity of all royleanone derivatives at position C-12. Further efforts are being undertaken to synthesize and evaluate the remaining compounds.

Table 4. P-gp inhibition in an MDR cancer cell line.

\begin{tabular}{|c|c|c|c|}
\hline Treatments & MFI $^{\mathbf{a}}$ & FAR $^{\mathbf{b}}$ & SI $^{\mathbf{c}}$ \\
\hline${\text { NCI-H460 } \text { control }^{\mathrm{d}}}^{\mathrm{N}}$ & 134.10 & -- & -- \\
\hline NCI-H460/R control $^{\mathrm{d}}$ & 16.96 & -- & -- \\
\hline Dex-VER $^{\mathrm{e}}$ & 36.07 & 2.13 & 26.90 \\
\hline $\mathbf{4}$ & 28.97 & 1.71 & 21.60 \\
\hline $\mathbf{5}$ & 35.54 & 2.10 & 26.50 \\
\hline
\end{tabular}

a The measured mean fluorescence intensity of Rhodamine 123 (MFI) was used for the calculation of the fluorescence activity ratio (FAR); ${ }^{\mathrm{b}}$ via the following equation: $\mathrm{FAR}=\mathrm{MFI}_{\mathrm{MDR}}$ treated $/ \mathrm{MFI}_{\mathrm{MDR}}$ control. $\mathrm{FAR}$ values above 1.50 indicate P-gp inhibition; ${ }^{c}$ The sensitivity index (SI) was calculated on the basis of the measured mean fluorescence intensity (MFI) expressed via the following equation: $\mathrm{SI}=\left(\mathrm{MFI}_{\mathrm{MDR} \text { treated }} * 100\right) / \mathrm{MFI}_{\text {sensitive }}$ control. SI values above 20 account for P-gp inhibition; ' Sensitive cancer cell line and its MDR counterpart used in the study: non-small cell lung carcinoma-NSCLC (NCI-H460 and NCI-H460/R); e Dex-VER was applied at the same concentration $(20 \mu \mathrm{M})$ as tested compounds.

Conclusions. The herein in silico studies provided valuable information to guide the design of future royleanone derivatives. While the analysis on local reactivity descriptors allowed us to understand possible degradation pathways and to guide further synthetic approaches towards new royleanone derivatives, molecular docking and MD studies further suggested that steric factors also play a role when choosing which substituent can be placed at position C-12. Furthermore, while the interaction with the substrate-binding $\mathrm{H}$ site suggests an additional competitive mechanism as the principal mode of action for $\mathrm{RoyBzCl}$ (4), favorable binding energies together with very high cross-interaction capabilities at the M-site (strong CIc) also allowed us to infer that compounds 4 and 5 (and its theoretical derivatives $\mathbf{4 a}, \mathbf{4 b}$ and 5a) may act as a non-competitive efflux modulators when bound to the M-site.

Therefore, a suitable approach for the future generation of novel derivatives will involve the selective modification of position C-12 with alternative substituents (e.g. unhindered 5to 6-member heterocycles, different linkers as amides or conjugation with aminoacids as glycine or glutamate) while varying the substitution pattern of the benzoyloxy moiety at position C-6.

\section{ASSOCIATED CONTENT}

Supporting Information
Computational details (methodology) on molecular descriptors calculations, molecular docking and molecular dynamics are provided, as well as details on the crystal structure of $\mathbf{5}$. Crystallographic information files were deposited at Cambridge Structural Database (CCDC 1986085). The Supporting Information is available free of charge on the ACS Publications website.

\section{AUTHOR INFORMATION}

\section{Corresponding Author}

* Patrícia Rijo, Universidade Lusófona de Humanidades e Tecnologias, Campo Grande, 376, 1749-024 Lisboa patricia.rijo@ulusofona.pt

* Ricardo J. Ferreira, Science for Life Laboratory, Department of Cell and Molecular Biology, Uppsala University, 75124 Uppsala, Sweden ricardo.ferreira@icm.uu.se

\section{Author Contributions}

The manuscript was written through contributions of all authors.

\section{Funding Sources}

Support for this work was provided by FCT through UID/DTP/04567/2019, PTDC/MED-QUI/30591/2017, UIDB/00100/2020, UIDP/00100/2020 and $\mathrm{PhD}$ grant SFRH/BD/137671/2018. The Academy of Finland is acknowledged for the financial support to N.R.C. (Decisions No. 326486/7) and Finnish Cultural Foundation for the financial support to S.H. (190336).

\section{ACKNOWLEDGMENT}

CSC-IT center for Science Ltd, Finland is acknowledged for the computational resources allocation.

\section{ABBREVIATIONS}

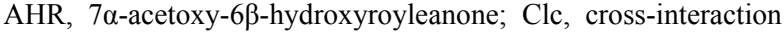
capability; Dex-VER, Dex-verapamil; DHR, 6,7-dehydroroyleanone; FAR, fluorescence activity ratio; $\Delta f_{k}$, dual descriptor; $\Delta G_{b i n d}$, relative free-energy of binding; HB, hydrogen bond; LE, ligand efficiency; $\log P$, octanol-water partition coefficient; MD, molecular dynamics; MDR, multidrug resistance; MFI, fluorescent intencity of Rhodamine-123; P-gp, P-glycoprotein; SI, sensitivity index.

\section{REFERENCES}

(1) Bray, F.; Ferlay, J.; Soerjomataram, I.; Siegel, R. L.; Torre, L. A.; Jemal, A. Global Cancer Statistics 2018: GLOBOCAN Estimates of Incidence and Mortality Worldwide for 36 Cancers in 185 Countries. CA. Cancer J. Clin. 2018, 68 (6), 394-424. https://doi.org/10.3322/caac. 21492.

(2) Dinić, J.; Podolski-Renić, A.; Jeremić, M.; Pešić, M. Potential of Natural-Based Anticancer Compounds for P-Glycoprotein Inhibition. Current Pharmaceutical Design. 2018, pp 4334 4354.

https://doi.org/http://dx.doi.org/10.2174/13816128256661901 12164211

(3) Deepali Waghray; Zhang, Q. Inhibit or Evade Multidrug Resistance P-Glycoprotein in Cancer Treatment. J Med Chem 2018, $61 \quad$ (12), 5108-5121. https://doi.org/10.1021/acs.jmedchem.7b01457. Faustino, C.; Francisco, A. P.; Isca, V. M. S.; Duarte, N. Cytotoxic Stilbenes and Derivatives as Promising Antimitotic Leads for Cancer Therapy. Current Pharmaceutical Design. 
2018 , pp

4270-4311.

https://doi.org/http://dx.doi.org/10.2174/13816128256661901 11123959.

Díaz, L. F.; Chiong, M.; Quest, A. F. G.; Lavandero, S.; Stutzin, A. Mechanisms of Cell Death: Molecular Insights and Therapeutic Perspectives. Cell Death Differ. 2005, 12, 1449.

(6) Rice, L. J.; Brits, G. J.; Potgieter, C. J.; Van Staden, J. Plectranthus: A Plant for the Future? South African J. Bot. 2011, 77 (4), 947-959. https://doi.org/10.1016/j.sajb.2011.07.001.

(7) Ladeiras, D.; M. Monteiro, C.; Pereira, F.; P. Reis, C.; A. M. Afonso, C.; Rijo, P. Reactivity of Diterpenoid Quinones: Royleanones. Curr. Pharm. Des. 2016, 22 (12), 1682-1714. https://doi.org/10.2174/1381612822666151211094521.

(8) Bernardes, C. E. S.; Garcia, C.; Pereira, F.; Mota, J.; Pereira, P.; Cebola, M. J.; Reis, C. P.; Correia, I.; Piedade, F. M.; Piedade, M. E. M. da; et al. Extraction Optimization, Structural and Thermal Characterization of the Antimicrobial Abietane $7 \alpha-$

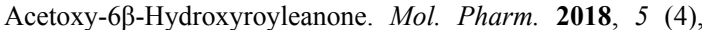
1412-1419.

(9) Burmistrova, O.; Simões, M. F.; Rijo, P.; Quintana, J.; Bermejo, J.; Estévez, F. Antiproliferative Activity of Abietane Diterpenoids against Human Tumor Cells. J. Nat. Prod. 2013, 76 (8), 1413-1423. https://doi.org/10.1021/np400172k.

(10) Rijo, P.; Matias, D.; Fernandes, A. S.; Simões, M. F.; Nicolai, M.; Reis, C. P. Antimicrobial Plant Extracts Encapsulated into Polymeric Beads for Potential Application on the Skin. Polymers (Basel). 2014, $6 \quad$ (2), 479-490. https://oi.org/10.3390/polym6020479.

(11) Kubínová, R.; Pořízková, R.; Navrátilová, A.; Farsa, O.; Hanáková, Z.; Bačinská, A.; Čížek, A.; Valentová, M.; Cížek, A.; Valentová, M.; et al. Antimicrobial and Enzyme Inhibitory Activities of the Constituents of Plectranthus Madagascariensis (Pers.) Benth. J. Enzyme Inhib. Med. Chem. 2014, $\quad 6366 \quad 15), \quad 1-4$ https://doi.org/10.3109/14756366.2013.848204.

(12) Rijo, P.; Duarte, A.; Francisco, A. P.; Semedo-Lemsaddek, T.; Simões, M. F. In Vitro Antimicrobial Activity of Royleanone Derivatives Against Gram-Positive Bacterial Pathogens. Phyther. Res. 2014, 28 (1), 76-81. https://doi.org/10.1002/ptr.4961.

(13) Rijo, P.; Simões, M. F.; Francisco, A. P.; Rojas, R.; Gilman, R. H.; Vaisberg, A. J.; Rodríguez, B.; Moiteiro, C. Antimycobacterial Metabolites from Plectranthus: Royleanone Derivatives against Mycobacterium Tuberculosis Strains. Chem. Biodivers. 2010, 7 (4), 922-932. https://doi.org/10.1002/cbdv.200900099.

(14) Garcia, C. Isolation, Synthesis and Nanoencapsulation of Cytotoxic Compounds from Plectranthus Spp., Doctoral dissertation. Universidad de Alcalá, Alcalá and Universidade Lusófona de Humanidades e Tecnologias, Lisbon, 2019.

(15) Garcia, C.; Isca, V. M. S.; Monteiro, C. M.; Sousa, F.; Ntungwe,
E.; Dinic, J.; Holmstedt, S.; Roberto, A.; Díaz-Lanza, A.; Reis, $\mathrm{C}$; et al. Royleanone Derivatives as a Novel Class of P-Gp Modulators: RoyBzCl a Potential Non-Competitive Efflux Modulator. Frontiers (Boulder). submitted

(16) Matias, D.; Nicolai, M.; Saraiva, L.; Pinheiro, R.; Faustino, C.; Diaz Lanza, A.; Pinto Reis, C.; Stankovic, T.; Dinic, J.; Pesic, M.; et al. Cytotoxic Activity of Royleanone Diterpenes from Plectranthus Madagascariensis Benth. ACS Omega 2019, 4 (5), 8094-8103. https://doi.org/10.1021/acsomega.9b00512.

(17) Parr, R. G.; Yang, W. Density Functional Approach to the Frontier-Electron Theory of Chemical Reactivity. J. Am. Chem. Soc. 1984, $106 \quad$ (14), 4049-4050. https://doi.org/10.1021/ja00326a036.

(18) Reed, A. E.; Curtiss, L. A.; Weinhold, F. Intermolecular Interactions from a Natural Bond Orbital, Donor-Acceptor Viewpoint. Chem. Rev. 1988, 88 (6), 899-926. https://doi.org/10.1021/cr00088a005.

(19) Morell, C.; Grand, A.; Toro-Labbé, A. New Dual Descriptor for Chemical Reactivity. J. Phys. Chem. A 2005, 109 (1), 205-212. https://doi.org/10.1021/jp046577a.

(20) Morell, C.; Grand, A.; Toro-Labbé, A. Theoretical Support for Using the $\Delta \mathrm{f}(\mathrm{r})$ Descriptor. Chem. Phys. Lett. 2006, 425 (4-6), 342-346. https://doi.org/10.1016/j.cplett.2006.05.003.

(21) Martínez-Araya, J. Why Is the Dual Descriptor a More Accurate Local Reactivity Descriptor than Fukui Functions? J. Math. Chem. 2014, 53 (2), 451-465.

(22) Ferreira, R. J.; Ferreira, M.-J. U.; dos Santos, D. J. V. A Insights on P-Glycoprotein's Efflux Mechanism Obtained by Molecular Dynamics Simulations. J. Chem. Theory Comput. 2012, 8 (6), 1853-1864. https://doi.org/10.1021/ct300083m.

(23) Ferreira, R. J.; Ferreira, M.-J. U.; dos Santos, D. J. V. A Molecular Docking Characterizes Substrate-Binding Sites and Efflux Modulation Mechanisms within P-Glycoprotein. J. Chem. Inf. Model. 2013, 53 (7), 1747-1760. https://doi.org/10.1021/ci400195v.

(24) Ferreira, R. J.; Ferreira, M.-J. U.; dos Santos, D. J. V. A. Do Adsorbed Drugs onto P-Glycoprotein Influence Its Efflux Capability? Phys Chem Chem Phys 2015, 17 (34), 2202322034. https://doi.org/10.1039/C5CP03216D.

(25) Suzuki, T.; Fukazawa, N.; San-nohe, K. Structure-Activity Relationship of Newly Synthesized Quinoline Derivatives for Reversal of Multidrug Resistance in Cancer. J Med Chem 1997, 40, 2047-2052.

(26) Ferreira, R. J.; dos Santos, D. J. V. A.; Ferreira, M.-J. U. PGlycoprotein and Membrane Roles in Multidrug Resistance. Futur. Med Chem 2015, $7 \quad$ (7), 929-946. https://doi.org/10.4155/fmc.15.36. 